\title{
The Acquisition of Phrasal Verbs through Cognitive Linguistic Approach: The Case of Iranian EFL Learners
}

\author{
Mohammad Javad Ansari \\ Sheikhbahaee University, Iran \\ E-mail: mohammadjavad57@gmail.com
}

Doi:10.7575/aiac.alls.v.7n.1p.185

URL: http://dx.doi.org/10.7575/aiac.alls.v.7n.1p.185
Received: 20/09/2015

Accepted: 08/12/2015

\begin{abstract}
Cognitive Linguistics has been applied in SLA in order improve the learning/acquisition process of foreign/second language. This quasi-experimental study was conducted to find the impact of the Cognitive Linguistics on learning/ acquiring the Phrasal Verbs among EFL learners at intermediate level. In this study the orientational metaphors were chosen because of their most- frequent usages. These particles were taught through Cognitive Linguistics for the experimental group and the results of the treatment were analyzed by the independent-samples $t$ test. The findings showed that through Cognitive Linguistics the acquisition of Phrasal Verbs were facilitated both in the exposed and unexposed ones. The results showed the positive effect of the Cognitive Linguistics. And finally this paper proposes some pedagogical implications for further study so as to crystalize the other features by means of Cognitive Linguistics.
\end{abstract}

Keywords: Cognitive Linguistics, phrasal verbs, metaphors, prototype theory, particles

\section{Introduction}

Gaining proficiency in L2 features such as grammatical features and vocabulary is often always is in the centre of language acquisition and English is not exempted from it. Traditional approaches and methods all have been applied to implement new ways in teaching in order to improve language performance among EFL/ESL. In most cases these approaches and methods consider the language as containing sub-categories and each of these sub-categories were taught separately, i.e. linguistic paradigm. But the result was not at satisfactory level and some other approaches and methods were proposed and developed by the scholars and the practitioners. One of them is Cognitive Linguistic approach. As Boers (2013) posits, "Cognitive Linguistics treats language and its acquisition as usage-based and as reflecting the general cognitive abilities that operate in our interaction with the world" (p. 211). The relationship between "cognitive competence" and "linguistic forms" is central to Cognitive Linguistics (Mitchell, Myles \& Marsden 2013). One of the features making learning English difficult is Phrasal Verbs (henceforth PVs). English learners complain that this feature is among the most difficult areas which cause them to feel uneasy with the target language learning. Among Persian-speaking learners of English PVs always lead the EFL learners to disappointment and, therefore, this paper tries to elaborate on Cognitive Linguistics in order to facilitate the acquisition of PVs. As said before, applying the formal instruction for teaching PVs proved that they had not been so efficient as expected and, thus, the other influential approaches and methods are needed for implementing PVs in the classroom. Cognitive Linguistics is the new school of linguistic thought which seeks to ease the process of teaching and learning. This smallscale study which is the quasi-experimental was conducted based on the Cognitive Linguistics to see whether the traditional method, here is the translation, has any priority over the Cognitive Linguistics. Therefore, six particles were chosen: across, up, down, off, in, and out. These are selected for two reasons:

1. They are considered the most frequent-used particles.

2. The treatment duration was scheduled for ten minutes.

The other argument is the criteria for the selection of the orientational particles and the rationale behind this selection. There is no rule-of-thumb to define the fixed frame for this selection. For example, Biber et al. (1999) argue that the most productive adverbial particles are as follows: up, out, on, in, off, and down, whereas in Collins Cobuild Dictionary (Sinclair (1989)) these particles are considered more productive: up, out, in, on and down. Anyhow, Lakoff and Johnson (2003) content that such metaphorical orientations [particles] have basis in the physical and cultural experience and are not arbitrary. They hold that metaphors are conceptual and our thoughts and acts are basically metaphorical. "To them, the essence of metaphor is understanding and experiencing one kind of thing in terms of another" (Imre, 2010). Therefore, besides up, down, off, in, and out, the particle across was selected to increase the learning load a bit.

\section{Literature Review}

\subsection{Cognitive Linguistics and the related issues}

Cognitive psychology represents the new era of thinking appeared to save the educational psychology (Brown, 2014). Cognitive Linguistics is a school of linguistics and cognitive science emerged from the early 1980s. When psychology 
and linguistics merged, this combination not only gave rise to psycholinguistics but also Cognitive Linguistics (Brown 2014). Gries (2008) states that Cognitive Linguistics is one of the alternatives to the linguistic paradigm of generative grammar proposed by Chomsky. Cognitive Linguistics is the study of language based on our experience of the world. This new alternative method has been seen as the complementary to other language methods by some scholars such as Talmy (2000). Ellis and Robinson (2008) acknowledge that Cognitive Linguistics seeks to go beyond the linguistic form "to further explain how language mutually interfaces with conceptual structure as this becomes established during child L1 development and as it becomes available for change during adult L2 language learning” (p. 4). Boers (2013) argues that the cognitive linguistic movement is a reaction to the generative linguistics:

The Cognitive Linguistic movement began mostly as a reaction to generative linguistics, which was felt to treat language too much as a special-purpose component, divorced from general cognition and the way language is actually cued. (p.211)

On the other hand, Lakoff (1987), and later on Tannen (1990) and Talmy (2003) examined the "cognitive and social backdrop of metaphor". "Cognitive Linguistics represents a contemporary approach to language, language learning, and conceptual structure" (Evans, 2012). It was a reaction to both generative grammar and formal semantics and, additionally, it is not a single theory but is a broad concept and, as Evans (2012) says, "wherein lies its strength" Later, it will be discussed in detail. Ellis (2013) notes that "cognitive linguistics and psycholinguistics have a role to play in informing the ordering of exemplars for optimal acquisition of a schematic construction" (p. 204). So, Cognitive Linguistics holds that learning language occurred from usage involving interplay of language usage and language processing and computational and statistical stimulations of acquisition (Ellis \& Robinson, 2008). According to Brown (2014, p. 89), the Cognitive Linguistics approaches are characterized by several themes as follows:

1. Language is not an autonomous faculty.

2. Syntax is not simply an arbitrary set of rules but rather is interwoven with conceptualization and knowledge.

3. Language ability cannot be examined without concurrent consideration of language use.

Then, the concepts of metaphor (embodiment), lexicon and grammar reality, concept formation, and usage as a cornerstone for understanding were incorporated by Holme (2012). Doughy and Long (2003) propose that the detailed qualitative analysis is provided by the Cognitive Linguistics in which language in the human is experience and embodiment. Cognitive Linguistics places the central role to the "meaning, conceptual processes, and embodied experience" in language and mind study (Evans, 2007).

Talmy (2000) highlights the notion that Cognitive Linguistics addresses the concerns of the following approaches: formal, psychological and conceptual. He goes further and says that the examining of the formal properties of language from its conceptual properties and the relating the findings to the cognitive structures are in the domain of Cognitive Linguistics.

Langacker (2010) holds that Cognitive Linguistics belongs to functionalism in contrast to formalism, thus, linguistic systems are analysed based on perception, attention, and categorization. Moreover, Cognitive Linguistics is not a single theoretical framework but it is consisted of two major principles: generalization commitment and cognitive commitment. These two sub-branches of Cognitive Linguistics are cognitive semantics and cognitive approaches to grammar. Janda (2010) acknowledges that "Cognitive Linguistics views linguistics cognition as an indistinguishable from general cognition and thus seeks explanation of linguistic phenomena in terms of general cognitive strategies" (p.1). She goes further and says that Cognitive Linguistics is a framework interacting with "academic allies". According to Janda (2010), Cognitive Linguistics tries to create analysis which is "psychologically plausible". In this connection, Ellis (2008) talks about the two different cognitive paradigms in the context of SLA: computational model and socioculctural account. He posits that both models share one point in common and believes that these models treat L2 acquisition as similar in nature to other kinds of learning in drawing on a common set of processes.

As earlier said, there are two key commitments of Cognitive Linguistics:

\section{Generalization Commitment}

\section{Cognitive Commitment}

Evans (2007) has provided the comprehensive and precise explanation for both of these concepts as follows that Generalization commitment is one of two key factors of the Cognitive Linguistics. He contends that Cognitive Linguistics "constitutes a commitment to the characterisation of general principles that are responsible for all aspects of human language" (p. 88). This type of commitment is based on the assumption the "general cognitive mechanisms and processes" are reflected in language. Accordingly, "search for common organising principles across different language "systems" is the interesting topic for the cognitive linguistics, such as phonology, syntax, semantics and so on. And finally he says that "such common organising principles include conceptual mechanisms like metaphor, conceptual blending and phenomena such as polysemy. The generalisation commitment stands in direct opposition to the modular approach taken in formal linguistics" (p. 89).

In other words, Gries (2008) argues that the generalization commitment "requires cognitive linguists to "characterize the general principles governing all aspects of human language' on all levels of description" (p. 408).

On the other hand, the explanation of the cognitive commitment according to Evans (2007, p. 19) includes as following that "[It] represents the view that the principles of linguistic structure should reflect what is known about human 
cognition from other disciplines, particularly the other cognitive sciences (philosophy, psychology, artificial intelligence and neuroscience)". He goes further and believes that the general principles should be reflected in cognitive commitment rather than the specific cognitive principles. This kind of commitment prominent in cognitive linguistics leads to generalisation commitments "the rejection by cognitive linguists of the modular approach to language and the mind adopted in formal linguistics.” (p. 19)

According to Gries (2008), “cognitive commitment requires linguists 'to make one's account of human language accord with what is generally known about the mind and brain"” (p. 408).

The other concept related to the Cognitive Linguistics is the Prototype theory. This theory uncovered in 1970s is one the main concepts taken up by Cognitive Linguistics development posited by Eleanor Rosch. Let's discuss this concept briefly. The concept of prototype in Cognitive Linguistics goes against the Classical Theory of Concepts. Lewandowska-Tomasczyk (2007) holds that the main tenet of Classical Theory of Concepts is "the definitional structure in the sense that they encode necessary and sufficient conditions for their application" (p.144). For example, bachelor is composed of a set of features: male, adult, and not married. Croft and Cruse (2004) state that the prototypes are the best examples of the categories. In contrast with this theory, the theoretical conception includes the following features proposed by Geeraerts (1989) (as cited in Lewandowska-Tomasczyk (2007, p. 145)):

a. Prototypical categories exhibit degrees of typicality; not every member is equally representative for a category.

b. Prototypical categories are blurred at the edges.

c. Prototypical categories cannot be defined by means of a single set of criterial (necessary and sufficient) attributes.

d. Prototypical categories exhibit a family resemblance structure, or more generally, their semantic structure takes the form of radial set of clustered and overlapping readings.

Some basic principles are also offered by prototype theory. According to Evans (2007), two basic principles were held by this theory: (1) cognitive economy and (2) perceived world structure. The former principle states that human being attempts to learn as much as possible from his/her environment "while minimizing cognitive effort and resources". The latter posits that "the world around us has correlational structure" (p. 176). But "today, prototype theory is no longer seen as an accurate view of categorization" (p. 177). However, as Geeraerts and Speelman (2010) acknowledge, "the linguistic development of prototype has brought to the attention a number of non-traditional semasiological features" (p. $24)$, but this paper is not going to discuss these features and they need another investigation.

Until 1990s, cognitive linguistics was static but by the innovation of construct grammar it became dynamic (Janda, 2010). In other words, the fixed rules cannot be assigned to Cognitive Linguistics but there are core concepts in Cognitive Linguistics. The merits of the Cognitive Linguistics include the following: data- and user-friendly of it (Janda, 2010). These core concepts, therefore, are descriptive not prescriptive and the empirical studies are the basic sources for them. So, there is always possible to add another concept fitting Cognitive Linguistics. Therefore, some scholars have used the term Cognitive Linguistics in order to influence on SLA and ESL/EFL teaching.

In this connection, some aspects of grammar are more difficult to teach and learn and the teachers and students complained about how to teach and learn these features. PVs are of one the difficult areas in English needed extra attention and according to Boers and Lindstromberg (2006) "particles in English phrasal verbs, and prepositions generally have been a favour object of CL-research into polysemy" (p. 318). According to Biber et al., (as cited in Putz (2007)), four major kinds of multiword combinations constitute the corpus-based grammar of spoken and written English: phrasal verbs, prepositional verbs, phrasal-prepositional verbs, and other multiword verb constructions. Putz (2007) states that PVs and prepositional verbs are two major areas of difficulty in language learning because their meanings cannot be derived from their individual elements and, on the other hand, they are required the special attention since they are frequently used in fiction and conversation. Wood (as cited in Herra (2013)) admits this difficulty and says that by gaining proficiency in PVs, the students' fluency in the target language will be increased. Condon (2008) argues that the arbitrariness of PVs combination and the random nature of particles (Side, 1990) make the acquisition of PVs more difficult for the EFL learners. The difficulty arises when we notice that the meanings of the individual words are different from their combination and PVs, therefore, are required to devise new approaches and methods for teaching. Thornbury (2002) has classified the lexical items into six most important chunks: collocations, PVs, idioms, sentence frames, social formulae, and discourse markers. He acknowledges that some chunks are transparent in meaning from their parts like as old as hill, whereas the meanings of the other chunks are not clear from their parts and thus are much more idiomatic such as PVs, knock off. He put in this way that:

Some phrasal verbs are syntactically flexible: I'll bring up the paper or I'll bring the paper up. Others are not: I can't tell the twins apart but not I can't tell apart the twins. Moreover, the combination bring up has a range of meanings, some literal (I'll bring up the paper), some semi-idiomatic (Don't bring that subject up again) and some very idiomatic (They brought their children up to speak Italian). (pp. 115-6)

He continues in this way that "phrasal verbs are another instance of fuzziness at the boundary between words and grammar" (p. 123). He provides some typical exercises used in teaching PVs. They are as follows: sentence-gap-fills, rephrasing, and matching.

To use the PVs as lexical chunks both accurately and appropriately distinguishes the advanced learners from intermediate ones, as Thornbury (2002) posits. The point here is that the superior results under experimental conditions 
disappear when they are applied in the real classroom and it is not unusual. But the pedagogical implications pave the ways for the instructors and practitioners to find the appropriate ways for teaching PVs.

The next point is that the Cognitive Linguistic experiment lasted for the short period of time and this may cause the results only be applicable in the laboratory situations. But its pedagogical implications are considerable and must be taken into account by the teachers and practitioners as well as the researchers. In one experiment, Condon (2008) conducted teaching PVs based on Cognitive Linguistic motivation lasted for two consecutive years, and the results illuminate the fact that the experimental group outperformed in both the pilot and the main experiment. And this shows that Cognitive Linguistic approach enhances the learning PVs. She came to this conclusion that the time investment has a significant advantage for the experiment group.

\subsection{Cognitive Linguistics and the Conducted Research}

Anyhow, a lot of scholars have conducted research in order to examine their new treatment for helping the students to overcome the obstacle, i.e. PVs. In the following lines some papers are discussed.

Yasuda (2010) conducted a study for teaching PVs based on the Conceptual Metaphor and the results offer support this notion that the "cognitive semantic approach is successfully transferrable" when language learners encounter with the novel PVs.

Schmid and Ungerer (2011) argued for the Cognitive Linguistics and language teaching and believed that the usageaccount of the first-language acquisition establishes the teaching principles and methods:

1. Practice and item-specification help to achieve the rule-based competence by induction.

2. The anchoring notion has the prominent role in Cognitive Linguistic approaches. That is to say, not only are the itemspecific structures represented in suitable situation, but also "their embedding in mind maps" is important equally, if not more.

According to Herra (2013), PVs could be taught through explicit and systematic learning and this proved that PVs through contextualized activities. Strong (2013) used sematic approach to teach PVs in which he selected three groups: Group one received paired-associate learning, group two semantic instruction with the meaning of the target particles, and group three received semantic analysis incorporated with image schema group. The results illustrated that regarding the exposed PVs all three groups perform equally. But in respect with the unexposed PVs, the results of the second and third groups' scores suggested that they did the test successfully. Therefore, Cognitive Linguistics approaches are effective on acquiring PVs.

The current study examined the learning and acquisition of PVs through cognitive linguistic approaches. After description of methodology and the results, in discussion section, the main points and the findings of the research would be explained. The point here is that instead of using the prototypical examples for the treatment group the less-frequent ones were used but as shown later the results were at satisfactory level. And this shows that the treatment is fundamental in acquiring PVs not the content of study.

Therefore, the following hypotheses were proposed so as to evaluate the effect of the new method in teaching PVs (the odd number was designated to the exposed PVs whereas the evens to the unexposed ones):

$H_{1}$ : The two groups will equally score well on the exposed PVS. That is to say, the familiarity influences on the performance of the students in the control and the experimental groups.

$H_{2}$ : The two groups will equally score poorly on the unexposed PVs. That is to say, the unfamiliarity has the negative effect on the performance of the students in the control and the experimental groups.

\section{Methodology}

\subsection{Subjects}

The participants were 30 university students studied in Qom Azad University with seven-year experience in English in high school. It was believed that they were in the same level of proficiency, i.e. intermediate because all of them took the Azad Entrance Exam. Anyhow, the Oxford Placement Test (2001) was used and those who scored +3 and above were selected. Most were between the ages19 and 35. Then the subjects were divided into two groups: the control and the experimental. The groups consisted of native Persian speakers enrolled in Education administration major. Each group consisted of two males and thirteen females. The session for each group lasted for 25 minutes.

\subsection{Procedure}

The orientational prepositions taught in this study included: across, up, down, off, in, and out. They were embedded in 36 sentences derived from the following sources:

1. The New Oxford Dictionary of English (1998)

2. Longman Exams Dictionary (2006)

3. Cambridge Academic Content Dictionary (2009)

4. Oxford Advanced Learner's Dictionary (2010)

The odd numbers belonged to the exposed category of PVs and the even numbers belonged to the unexposed category of PVs. That is to say, the test consisted of two parts: the exposed and the unexposed PVs. Half of the test consisted of exposed PVs and the remaining one the unexposed PVs. The testees were not aware of this distribution. 
In the control group, the subjects received the translation of the orientational particles with their verbs for 10 minutes and 5 minutes was given for review the exposed orientational PVs and 10 minutes for the test which contained eighteen unexposed orientational PVs as well as eighteen exposed ones (Appendix II). Before the test, they were given the checklist in which the exposed PVs, i.e. the odd number, were written and the students had to write the meaning as the teacher translated the PVs.

On the other hand, for the experimental group the new way of PVs teaching was introduced, that is to say, Cognitive Linguistics. In this treatment, the subjects received the new explanation based on the teacher's classification of the target particles based on their meanings and besides this explanation, the visual aids were also used in order to crystalize the students' understanding of PVs and be sure that they learned the concepts vigorously. In addition, one example was given for each particle which was not essentially the prototypical ones (Appendix I). Like the control group, the time allocation for implementing the new treatment was 25 minutes like the control group. The checklist was given to the students in which the exposed PVs were written on the page and the new instruction was conducted by the teacher and the subjects had to think deeply about the particles, that is, instead of focusing on PVs' meanings, the main attention was given to the particles and their meanings. In other words, the particles were explained and categorized according to their functions and the subjects had to work with these concepts so as to crystalize them in their mind. Besides this procedure, the visual aids were also used to make sure that the treatment work effectively.

For the final test in addition to the exposed category of PVs, the unexposed category was included in order to see the possible performance difference. The aim of unexposed PVs was to investigate whether the participants would be able to apply new treatment to new PVs with same particles.

And the format of the test was fill-in-the-blank. The statistical analysis is based on independent-samples t test in SPSS 22 because there were two items (exposed and unexposed PVs) with two groups (control and experimental). The alpha level was set at 0.05 .

\section{Results}

As previously shown, two questions posited by this paper are as follows:

1. Do these two groups _the control and the experimental_perform equally well on the Cognitive Linguistic-related approaches?

2. Do these two groups score poorly on the unexposed PVs based on the Cognitive Linguistic-related approaches?

This section is divided into two parts: (a) Exposed (i.e. seen) PVs; and (b) Unexposed (i.e. unseen) PVs.

\subsection{Exposed PVS}

The descriptive results of the exposed PVs have been summarised in Table 1 and Table 2 for both the control and the experimental groups, respectively. In these tables the number of students, minimum and maximum, mean and the standard deviation were reported. The tables show that the experimental group drastically better performed in the exposed PVs (regarding the mean of the control group, 7.4, and the experimental group, 16.67). Moreover, by comparing the minimum and the maximum scores, the differences between these two groups were evident. The compared means of the both groups reveals that there is great distance between them and it appears that this existing distance is related to the way of presenting the PVs. The interesting point here is that in the experimental group there were some cases in which scored the highest point, i.e. 18.

Table 1. Descriptive Statistics of the Experimental Group for the Exposed Phrasal verbs

\begin{tabular}{lccccc}
\hline & $\mathrm{N}$ & Minimum & Maximum & Mean & SD \\
\hline Exposed & 15 & 3.00 & 15.00 & 7.4000 & 3.85079 \\
\hline
\end{tabular}

Table 2. Descriptive Statistics of the Experimental Group for the Exposed Phrasal verbs

\begin{tabular}{lccccc}
\hline & $\mathrm{N}$ & Minimum & Maximum & Mean & SD \\
\hline Exposed & 15 & 13.00 & 18.00 & 16.6667 & 1.83874 \\
\hline
\end{tabular}

Then the statistical data were analysed according to the independent-samples t test and the results are given in the Tables 3 and 4. The SD and SEM are also provided in addition to the mean in Table 3.

Table 3. The Statistical Description of the Control and Experimental Groups in Exposed PVs

\begin{tabular}{lllll}
\hline & $\mathrm{N}$ & Mean & SD & SEM \\
\hline Control & 15 & 7.4000 & 3.85079 & 0.99427 \\
Experimental & 15 & 16.6667 & 1.83874 & 0.47476 \\
\hline
\end{tabular}


Based on the Table 4, because the significant level is less than 0.05 , we can assume that the group variances are not equal and need to use the second column of t-test results. In our study, we have a t obtained of -8.410 , and with 20.069 degrees of freedom, it is significant at the 0.000 level.

Table 4. Independent Samples t test for Exposed PVs

\begin{tabular}{|c|c|c|c|c|}
\hline \multicolumn{4}{|c|}{ Equal variances assumed } & \multirow[t]{3}{*}{ Equal variances not assumed } \\
\hline \multirow{2}{*}{\multicolumn{2}{|c|}{ Levene's Test for Equality of Variables }} & $\mathrm{F}$ & 9.993 & \\
\hline & & Sig. & 0.004 & \\
\hline \multirow[t]{7}{*}{ t-test for Equality of Means } & $\mathrm{t}$ & & -8.410 & -8.410 \\
\hline & $\mathrm{df}$ & & 28 & 20.069 \\
\hline & Sig & iled) & 0.000 & 0.000 \\
\hline & $\mathrm{Me}$ & ference & -9.26667 & -9.26667 \\
\hline & Std & Difference & 1.10180 & 1.10180 \\
\hline & $95^{\circ}$ & fidence lower Mean & -11.52361 & -11.56448 \\
\hline & Inte & the upper Mean & -7.00973 & -6.96885 \\
\hline
\end{tabular}

Thus we can conclude that these two groups are significantly different with respect to the new method applied and, therefore, the first null hypothesis is rejected and we can say that:

The two groups did not equally score well on the exposed PVS. That is to say, the familiarity did not influence on the performance of the students in the control and the experimental groups and the experimental group outperformed than the control group.

\subsection{Unexposed PVS}

The descriptive results of the unexposed PVs have been summarised in Table 5 and Table 6 for the control and the experimental groups, respectively. In these tables the number of students, minimum and maximum, mean and the standard deviation were reported. The tables show that the experimental group drastically better perform in the unexposed PVs (regarding the mean of the control group, 6.5333, and the experimental group, 13.8667). The compared means of the both groups reveals that there is great distance between them and it appears that this distance is rooted to the way of presenting the PVs. The point worth mentioning here is that none of the students in both groups scored the highest point and this proposes that it needs another research to find the reason for this shortcoming in order to improve the students' ability to score the highest point.

Table 5. Descriptive Statistics of the Experimental Group for the Unexposed Phrasal verbs

\begin{tabular}{llcccc}
\hline & $\mathrm{N}$ & Minimum & Maximum & Mean & SD \\
\hline Exposed & 15 & 2.00 & 12.00 & 6.5333 & 3.35659 \\
\hline
\end{tabular}

Table 6. Descriptive Statistics of the Experimental Group for the Unexposed Phrasal verbs

\begin{tabular}{lccccc}
\hline & $\mathrm{N}$ & Minimum & Maximum & Mean & SD \\
\hline Exposed & 15 & 8.00 & 16.00 & 13.8667 & 2.53170 \\
\hline
\end{tabular}

Then the results of both groups were analysed based on independent-samples t test, and the results is provided by the tables 7 and 8 . Like table 3, the table 7 illustrates the mean, SD, and SEM of both groups:

Table 7. The Statistical Description of the Control and Experimental Groups in Unexposed PVs

\begin{tabular}{lllll}
\hline & $\mathrm{N}$ & Mean & SD & SEM \\
\hline Control & 15 & 6.5333 & 3.35659 & 0.86667 \\
Experimental & 15 & 13.8667 & 2.53170 & 0.65368 \\
\hline
\end{tabular}

Based on the Table 8 , because significant level is greater than 0.05 , we can assume that the group variances are equal and need to use the first column of t-test results. In our study we have a t obtained of -6.755 and with 28 degrees of freedom $(\mathrm{df}=\mathrm{n}-2)$, it is significant at the 0.000 level. 


\begin{tabular}{|c|c|c|c|c|}
\hline \multicolumn{4}{|c|}{ Equal variances assumed } & \multirow[t]{3}{*}{ Equal variances not assumed } \\
\hline \multirow{2}{*}{\multicolumn{2}{|c|}{ Levene's Test for Equality of Variables }} & $\mathrm{F}$ & 2.430 & \\
\hline & & Sig. & 0.130 & \\
\hline \multirow[t]{7}{*}{ t-test for Equality of Means } & $\mathrm{t}$ & & -6.755 & -6.755 \\
\hline & df & & 28 & 26.034 \\
\hline & Sig. & iled) & 0.000 & 0.000 \\
\hline & $\mathrm{Me}$ & ference & -7.33333 & -7.33333 \\
\hline & Std. & Difference & 1.08555 & 1.08555 \\
\hline & $95 \%$ & fidence lower Mean & -9.55698 & -9.56456 \\
\hline & Int & of the upper Mean & -5.10969 & -5.10210 \\
\hline
\end{tabular}

Thus, we can conclude that these two groups are significantly different with respect to the new method applied and therefore the second null hypothesis is also rejected and we can say that:

The experimental group outperformed with respect to the unexposed PVS. That is to say, the unfamiliarity had the negative effect on the performance of the students in the control group but for the experimental group it made no changes.

In sum, it became obvious that the experimental group did better on the PVs test than the control group both in the exposed_seen_and unexposed_unseen.

\section{Discussion and conclusion}

The premise of this study was to investigate the Cognitive Linguistics impact on learning/ acquiring the grammatical features, here PVs. This study showed that for internalizing PVs the Cognitive Linguistic approach was the mostinfluential device and the teachers and instructors are recommended to use it so as to teach the PVs. The results of this study also postulate this assumption that applying the Cognitive Linguistics in teaching (here, PVs) facilitates the acquisition of problematic features of L2 and as the experimental group of this study showed their performance were better than the control group in which the traditional method, i.e. translation was used to teach the PVs. The findings indicated that the experimental group performed better in the eighteen exposed PVs than the control group and this suggests that the new treatment has had the positive effect on the process of learning and acquisition of PVs. Although both of these two groups were familiar with this type of question they saw them before - the performance was meaningfully different when the comparison was made. Furthermore, this difference reveals this fact that the retention is much more considerable among the students of the experimental group received the new treatment by means of Cognitive Linguistic approach. Thus, we can come to this conclusion that the Cognitive linguistics helps the student to learn/ acquire the problematic features in SLA. Regarding the second hypothesis, again it became obvious that the experimental group scored better than the control groups in eighteen unexposed unseen_ PVs and therefore the positive influence of the cognitive linguistics was evident in this study. As Ellis (2003) acknowledges that the principle of the cognitive linguistics is based on this fact that the language cognition cannot be separated from semantics and the rest of the cognition.

All in all, the findings illustrate that the role of the Cognitive Linguistics is prominent and it helps the learners to acquire the problematic features of English at the satisfactory level. Cognitive Linguistics helps the learner to link the form to the meaning of the holistic unit. And building up this direction often always influences the examinee's performance. The important implication of the new treatment _ Cognitive Linguistic-related approaches is the concept of autonomy. Dornyei (2014) assumes that when the students feel some sort of ownership they are motivated to pursue the tasks, as he states, "autonomy and motivation go hand in hand" (526). In Cognitive-linguistic-related approach it seems that the treatment group became aware of the nature of the particles and their relation with the verb, they would be able to understand the meanings of the PVs.

The point worth mentioning here is that in choosing the particles, it makes no different whether to choose the most productive particles or the less-frequent ones such as the particle across. The other research which was carried out in this field and discussed in this paper previously used the most prototypical examples while in this study the researcher used the less-common instances but the overall results were not meaningfully different from the results of the other research counterparts. Of course, the further research has to be conducted to crystalize this claim. And this fact articulates this notion that the vital point in learning the PVs is the way of teaching _ here is the Cognitive Linguistic Approach _ not the selection of the grammatical features, that is, the particles.

What the results imply is that the students could acquire PVs through Cognitive Linguistics and elaborated on them in the written exercises, but whether they will be able to use them orally (i.e. conversation) needs to carry out another study and it is beyond the scope of this research. The main limitation of this study, at least to me, is the number of students. It seems that for rigorous results, the longitudinal study is plausible in determining the effect of the new treatment. Anyhow, the pedagogical implications of such studies have begun the new era for the further sophisticated research. The other issue related to the experimental group is that the students could retrieve the correct particles from 
their memory even in some cases they did not know the exact meanings of the verbs. This phenomenon verifies the role of Cognitive Linguistics on the long-term memory in which the information can be stored in it and the learners can use this information whenever they need. Moreover, the concepts of receptive and productive skills arise here. This is beyond the scope of this study to answer this question whether the Cognitive Linguistics' role is more prominent in receptive or productive skills, as said before, another study has to be carried out. But regardless of speaking and writing abilities, the receptive skills precede the productive one in this case. The further research needs to be conducted in this field in the case of other features like articles. The outcomes of such studies pave the way for better understanding of SLA. And they also point out that whether the problematic areas of language could be facilitated by means of new treatment. Regarding the matter of explicitness or implicitness, based on the findings of this paper, explicitness is more effective than the opposite one; and Ellis (2012) postulates this notion by reviewing the experimental and quasiexperimental investigation into the L2 instruction effectiveness and comes to this conclusion that the explicit instruction is more effective that the implicit type.

In total, the effect of Cognitive Linguistics is more prominent and its role cannot be neglected. It goes without saying that, Cognitive Linguistics in the field of SLA could have positive effect, at least, until now, according the findings of the current study and the previous ones. And last but not least, instead of considering the Cognitive Linguistics as a new method it is recommended that it should be used as a complementary aid besides the other approaches and methods. In this case, the further research will be required. And in the end, Lantolf (2011) properly states that cognitive linguistics provides potentially useful sources of scientific knowledge of the concept under study for language instruction.

\section{References}

Boers, F. (2013). Cognitive linguistic approaches to teaching vocabulary. Language Teaching, Volume 46(2), $208-224$.

Boers, F., \& Lindstromberg (2006). Cognitive linguistic applications in second or foreign language instruction: rationale, proposals, and evaluation. In G. Kiristiansen, G., M. Achard, R. Driven., \& F. J. R. de Mendoza Ibanez (Eds.), Cognitive linguistics: current applications and future perspectives (pp. 305- 355). Berlin: Walter de Gruyter $\mathrm{GmbH} \& \mathrm{Co}$.

Boers, F., \& Lindstromberg, S. (2008). Cognitive linguistic approaches to teaching vocabulary and phraseology. Berlin: Mouton de Gruyter.

Brown, D. H. (2014). Principles of language learning and teaching. New York: Pearson Education.

Condon, N. (2008). How cognitive linguistic motivations influence the learning of phrasal verbs. In F. Boers \& S. Lindstromberg (Eds.), Cognitive linguistic approaches to teaching vocabulary and phraseology (pp.133-158). Berlin: Mouton de Gruyter.

Croft, W., \& Cruse D. A. (2004). Cognitive linguistics. Cambridge: Cambridge University Press.

Dornyei, Z. (2014). Motivation in second language learning. In M. Celce-Murcia, D. M. Brinton, \& M. A. Snow (Eds.), Teaching language as a second or foreign language (4 ${ }^{\text {th }}$ edition) (pp. 518-531). Boston: National Geographic Learning.

Ellis (2003). Constructions, chunking, and connsctionism: The emergence of second language structure. In C. J. Doughty \& M. H. Long (Eds.), The handbook of second language acquisition. Malden: Balckwell Publishing Ltd.

Ellis, N. C. (2012). Frequency-based accounts of second language acquisition. In S. M. Gass \& A. Mackey (Eds.), The Routledge handbook of second language acquisition (pp. 193-210). Abingdon: Routledge.

Ellis, N. C., \& Robinson, P. (2008). An introduction to cognitive linguistics, second language acquisition, and language instruction. In P. Robinson \& N. C. Ellis (Eds.), Handbook of cognitive linguistics and second language acquisition (pp. 3-24). New York: Routledge.

Ellis, R. (2008). The study of second language acquisition. Oxford: Oxford University Press.

Evans, V. (2007). A glossary of cognitive linguistics. Edinburgh: Edinburgh University Press.

Evans, V. (2012). Cognitive Linguistics. Retrieved from http://wires.wiley.com/cogsci/

Geeraerts D., \& Speelman D. (2010). Heterodox concept features and onomasiological heterogeneity in dialect. In D. Geeraerts, G. Kristiansen, \& Y. Peirsman (Eds.), Advances in cognitive sociolinguistics (pp. 23-39). Germany: Mouton de Gruyter.

Gries, S. T. (2008). Corpus-based methods in analyses of second language acquisition data. In P. Robinson \& N.C. Ellis (Eds.), Handbook of cognitive linguistics and second language acquisition (pp. 406-431). New York: Routledge.

Herra, C.R. (2013). Phrasal verbs: Their teaching and acquisition. Revisita De Lenguas Modernas. 487-59. Retrieved from http://revistas.ucr.ac.cr/

Imre, A. (2010). Metaphors in cognitive linguistics. Eger Journal of English Studies X, 71-81. Retrieved from http://anglisztika.ektf.hu/

Janda, L. A. (2010). Cognitive linguistics in the year 2010. International Journal of Cognitive Linguistics. Volume 1, Issue 1. 1-30. New York: Nova Science Publisher, Inc.

Lakoff, G., \& Johnson, M. (2003). Metaphor we live by. London: University of Chicago Press. 
Langacker, R.W. (2010). Conceptualization, symbolization, and grammar. International Journal of Cognitive Linguistics. Volume 1, Issue 1. 31-63. New York: Nova Science Publisher, Inc.

Lantolf, J. P. (2011). The sociocultural approach to second language acquisition. In D. Atkinson (Ed.), Alternative approaches to second language acquisition (pp. 24-46). Abingdon: Routledge.

Lewandowska-Tomaszczyk, B. (2007). Polysemy, prototypes, and radial categories. In D. Geerarets \& H. Cuyckens (Eds.), The Oxford handbook of cognitive linguistics (pp. 139-169). Oxford: Oxford University Press.

Mitchell, R., Myles, F., \& Marsden, E. (2013). Second language learning theories. Abingdon: Routledge.

Putz, M. (2007). Cognitive linguistics and applied linguistics. In D. Geerarets \& H. Cuyckens (Eds.), The Oxford handbook of cognitive linguistics (pp. 1139- 1159). Oxford: Oxford University Press.

Ran, B., \& Duimering P. R. (2010). Conceptual combination: models, theories, and controversies. International Journal of Cognitive Linguistics. Volume 1, Issue 1, 65-90. New York: Nova Science Publisher, Inc.

Schmid, H.J., \& Ungerer, F. (2011). Cognitive linguistics. In J. Simpson (Ed.), The Routledge handbook of applied linguistics (pp.611-624). Abingdon: Routledge.

Strong, B. (2013). A cognitive semantic approach to L2 learning of phrasal verbs. The language Teacher. September/October. Retrieved from http://jalt-publications.org/

Talmy, L. (2000). Toward a cognitive semantics. Massachusetts Institute of Technology. Retrieved from http://linguistics.buffalo.edu/

Thornbury, S. (2002). How to teach vocabulary. Edinburgh: Pearson Education.

Yasuda, s. (2010). Learning phrasal verbs through conceptual metaphors: a case of Japanese EFL learners. TESOL QUARTERLY , 44(2).

\section{Appendix I}

\section{ACROSS}

- from one side to the other side

travel across

DOWN

- towards or in a lower place or position, esp. to or on the ground or another surface

- to or at a lower level of intensity, volume, or activity

bend down

$\underline{\mathrm{IN}}$

- $\quad$ expressing movement with the result that someone or sth becomes enclosed

- $\quad$ expressing the situation of being enclosed or surrounded by sth

lock in

$\underline{\mathrm{OFF}}$

- away from the place in question

- $\quad$ so as to bring to an end or be disconnected

fall off

$\underline{\text { OUT }}$

- moving or appearing to move away from a particular place

- away from one's unusual base/residence

come out

$\underline{\mathrm{UP}}$

- at or to a higher level of intensity, volume, or activity

- towards the sky or a higher position

lead up 
Appendix II

- Fill the blanks with the appropriate particles:

\section{across up down off in out}

1. He jumped ......from his car.

2. We were locked.....

3. I called him but he ran......

4. She ran.....into the corridor.

5. He look ....... at her.

6 . The kids were playing by the river and one of them fell.....

7. It's too wide. We can't swim...........

8. We watched the sun went.......

9. Keep ......the grass.

10. She jump..... of the chair.

11. Some coins fell .....from my bag.

12. She walked........the bridge.

13. Let's go.....this evening.

14. They live..... in the mountains.

15 . Turn ...... the radio.

16. I pinned the notice...... on the wall.

17. Someone parked right ........... the entrance to the driveway.

18. Pick....your clothes and put them away.

19. The roof of their house caved..... during a hurricane.

20 . She opened it and took ..... pair of shoes.

21 . How many days did you take.....?

22. When my name was called, he looked......... at me.

23. Could you bring the clothes...for me?

24. He got into his car and drove.

25. Please sit.

26. You look nice with your hair.....

27. Fill.....your name and address on the form provided.

28. They can't swim.

29 . Was the computer on or........when you left?

30. Tears were streaming .......my face.

31. I must be ........now.

32. I am going .......for a walk.

33. When's her flight due....?

34. Lay cards face......

35. They ran straight.......the road.

36. I got ....... of the bed. 